\title{
Effect of normobaric hypoxia on cardiorespiratory and metabolic risk markers in healthy subjects
}

\author{
Bateer Shi, Tsuneo Watanabe*, Sohee Shin, Tamotsu Yabumoto, Toshio Matsuoka \\ Department of Sports Medicine and Sports Science, Gifu University Graduate School of Medicine, Gifu, Japan \\ Email: *tsuneo_w@gifu-u.ac.jp
}

Received 6 January 2013; revised 7 February 2013; accepted 20 February 2013

\begin{abstract}
The aims of this study were to investigate the influence of hypoxic physical exercise on metabolic risk markers and to compare the effects on maximum oxygen uptake $\left(\mathrm{VO}_{2 \max }\right)$, arterial stiffness, and several blood parameters to a control group training under normoxic conditions. Eight healthy men were examined. Each participant performed exercise at a heart rate (HR) corresponding to $60 \%$ of the $\mathrm{HR}$ at $\mathrm{VO}_{2 \max }$ on a treadmill device for 50 min (including $5 \mathrm{~min}$ warm-up and $5 \mathrm{~min}$ cool-down) after $30 \mathrm{~min}$ rest, on 3 days per week, for 4 weeks, in either normobaric hypoxia or normobaric normoxia. Each participant performed the exercise program under both environmental conditions with a wash-out period of 4 months. Brachial ankle pulse wave velocity after training was significantly lower in the hypoxic group than in the normoxic group $(P=0.02)$. The $\mathrm{VO}_{2 \max }$ in the hypoxic group was significantly higher after than before training $(P=0.04)$. Our results suggest that hypoxic training may more effectively reduce arterial stiffness and improve cardiorespiratory function compared with training performed at the same relative exercise intensity under normoxic conditions.
\end{abstract}

Keywords: Metabolic Syndrome; Maximum Oxygen Uptake; Hypoxic Training; Arterial Stiffness

\section{INTRODUCTION}

Metabolic syndrome (MS) is a constellation of obesity, hyperglycemia, decreased high-density lipoprotein (HDL), increased triglyceride, and high blood pressure. Thus, MS represents a group of risk factors that increases the risk of heart disease and other health problems, such as diabetes mellitus (DM) and stroke [1]. The associations of these factors with each other and with health problems have been recognized for decades. The frequencies of these risk factors have clearly demonstrated that MS is

*Corresponding author. common and has a rising prevalence worldwide, which relates largely to increasing obesity and sedentary lifestyles [2], with different regions having individual clusters of epidemic risk factors [3]. As a result, MS is now in the spotlight as both a public health and a clinical problem.

Physical activity is widely acknowledged to reduce the risk of cardiovascular disease in individuals with established disorders such as obesity, hypertension, DM, and hyperlipidemia [4-9]. Meanwhile, new alternatives for traditional altitude training regimes have been proposed, known as "living low and training high", and the effects on endurance performance have been demonstrated extensively in athletes [10-12]. Recently, several studies have reported the effects of hypoxia training on physical fitness not only in athletes but also in nonathletes [13-17]. In obese subjects, body weight was significantly decreased in subjects with hypoxia training compared with that in subjects with normoxia training [14]. Recent studies have also reported that hypoxic training could more effectively reduce arterial stiffness in postmenopausal women compared with that in normoxic training [17]. However, although body weight changes during high-altitude mountain expeditions have been described in several studies for healthy subjects $[18,19]$, there have been very few reports on hypoxic training effects under controlled experimental conditions. The purpose of this study was to investigate the influence of hypoxic physical exercise on metabolic risk markers and to compare the effects on maximum oxygen uptake $\left(\mathrm{VO}_{2 \max }\right)$, arterial stiffness, and several blood parameters related to MS to a control group training under normoxic conditions.

\section{MATERIALS AND METHOD}

\subsection{Subjects}

Eight healthy men (age: $25.8 \pm 7.8$ years, height: $174.9 \pm$ $5.3 \mathrm{~cm}$, weight: $71.4 \pm 14.5 \mathrm{~kg}$, body mass index [BMI]: $23.4 \pm 4.6 \mathrm{~kg} / \mathrm{m}^{2}$ ) with no history of cardiopulmonary disease and no pathogenic conditions affecting the musculoskeletal or neuromuscular system volunteered to par- 
ticipate in this study. They were asked to continue with their customary diet/nutrition that they were following before the study. All subjects provided informed consent as required by the university institutional review board, which approved the study.

Prior to the study, all subjects received a medical examination, which included electrocardiography and echocardiography at rest. In all 8 subjects, spiroergometry was performed to determine the $\mathrm{VO}_{2 \max }$ during exercise, and the training level for each study participant was set as $60 \%$ of the heart rate $(\mathrm{HR})$ at $\mathrm{VO}_{2 \max }$.

\subsection{Study Parameters}

Study parameters were as follows: body weight, height, $\mathrm{BMI}$, body fat, waist circumference, $\mathrm{VO}_{2 \max }$, ultrasonographic findings, arterial stiffness measurements, and findings of laboratory blood tests. The blood laboratory test included the following biochemical markers: total cholesterol (TCHO), HDL cholesterol, low-density lipoprotein (LDL) cholesterol, triglycerides (TG), fasting glucose, fasting insurin, and glycosylated hemoglobin (HbA1c). The homeostasis model assessment (HOMA) index of insulin resistance was also calculated from fasting insulin and glucose data with the following formula: insulin $(u \mathrm{U} / \mathrm{mL}) \times$ glucose $(\mathrm{mg} / \mathrm{dL}) / 22.5$. Height, bodyweight, body fat, and blood pressure were measured using a regular medical scale. All study parameters were measured before and after the 4-week trial.

\section{3. $\mathrm{VO}_{2 \max }$ Measurements}

$\mathrm{VO}_{2 \max }$ was measured using the modified Astrand protocol [20]. Participants ran at 70\% maximum HR for 3 min; the angle of the gradient was then increased by $2 \%$ every 2 min until exhaustion. Using this protocol and a constant speed carries a slight risk of falling while running, but $\mathrm{VO}_{2 \max }$ can be measured accurately within a short time. $\mathrm{VO}_{2}$ was recorded continuously using a "breathby-breath” method, and HR was measured simultaneously. In addition, ratings of perceived exertion during $\mathrm{VO}_{2 \max }$ measurement were recorded every 2 min by a research investigator.

\subsection{Ultrasonographic Evaluation}

Ultrasound examination of the abdomen was performed by a board certified sonographer using a $6.0-14.0 \mathrm{MHz}$ linear array probe (portable real-time apparatus: LOGIQ $e$; GE Healthcare Corp., Tokyo, Japan). Both preperitoneal and subcutaneous fat thicknesses were measured according to the criteria of Suzuki et al. [21]. Longitudinal scanning was performed along the linea alba from the xiphoid process to the umbilicus with the subject in a supine position. The probe was maintained to make con- tact as light as possible so as not to compress the fat layer. The maximum thickness of preperitoneal fat $\left(\mathrm{P}_{\max }\right)$, and the minimum and maximum thicknesses of subcutaneous fat $\left(S_{\min }\right.$ and $S_{\max }$, respectively), were measured.

\subsection{Arterial Stiffness Measurement}

Brachial ankle pulse wave velocity (PWV) and ankle brachial index (ABI), representing arterial stiffness, were measured noninvasively with subjects in the supine position and a form-I automated PWV/ABI analyzer (Colin co. Ltd., Komaki, Japan) attached to the 4 limbs [22].

\subsection{Protocol}

This study consisted of a same-subject repeated-measures design with the independent variable being the environmental condition (normoxia or hypoxia) and several parameters related to $\mathrm{MS}$ and $\mathrm{VO}_{2 \max }$ as the dependent variables. The examinations were conducted in a controlled environment with the temperature maintained at $22^{\circ} \mathrm{C}$, and the 2 training programs with different environmental conditions were performed with a 4-month wash-out period. Each participant performed exercise at a HR that corresponded to $60 \%$ of the $\mathrm{HR}$ at $\mathrm{VO}_{2 \max }$ on a treadmill device for 50 min (including 5 min warm-up and 5 min cool-down) after 30 min rest, on 3 days per week, for 4 weeks, in either normobaric hypoxia $(15.4 \%$ $\mathrm{O}_{2}$, equivalent to $2500 \mathrm{~m}$ altitude) or normobaric normoxia (20.9\% $\mathrm{O}_{2}$, the altitude at the study location). All subjects were required to rest for 30 min after the exercise session. During the exercise session, HR was monitored to ensure that exercise intensity never exceeded $60 \%$ of the maximum HR. Subjects were questioned about the presence of the major symptoms of acute altitude sickness (headache, nausea, and weakness in the legs not usually experienced during exercise); $\mathrm{SaO}_{2}$ was also monitored for safety reasons.

\subsection{Statistical Analysis}

Results are presented as mean \pm standard deviation (SD), and statistical significance was determined at $P<0.05$. A two-way factorial analysis of variance (ANOVA) test was used to determine differences between several parameters $(2 \times 2$; normoxia/hypoxia $\times$ before/after training). Tukey's HSD test was applied to assess differences among multiple comparisons when ANOVA indicated a significant difference for a factor. The statistical program used for the calculations was IBM SPSS version 19.0 (IBM SPSS, Chicago, IL).

\section{RESULTS}

Demographic and physiological baseline characteristics for both training groups are shown in Table 1. Before 
Table 1. Subjects characteristics.

\begin{tabular}{ccc}
\hline Parameter & Hypoxia Group & Normoxia Group \\
\hline Men (n) & 8 & 8 \\
Age (years) & $25.8 \pm 7.8$ & $26.4 \pm 7.7$ \\
Height $(\mathrm{cm})$ & $174.9 \pm 5.3$ & $174.9 \pm 5.3$ \\
Weight $(\mathrm{kg})$ & $71.4 \pm 14.5$ & $70.9 \pm 13.3$ \\
BMI $\left(\mathrm{kg} / \mathrm{m}^{2}\right)$ & $23.4 \pm 4.6$ & $23.2 \pm 4.3$ \\
Body fat $(\%)$ & $20.0 \pm 8.3$ & $19.9 \pm 8.1$ \\
\hline
\end{tabular}

training, no significant differences in any values were identified between groups. Measurements for several parameters according to group and before/after training are shown in Table 2. Significant interactions were observed for the $\mathrm{ABI}[\mathrm{F}(1,7)=7.88, P=0.03]$. No significant main effects or interactions were observed for body weight, BMI, body fat, waist circumference, $S_{\min }$, $\mathrm{P}_{\max }$, and laboratory parameters. Despite no significant main effects among the groups, a significant main effect for before/after training was observed for $\mathrm{S}_{\max }[\mathrm{F}(1,7)=$ 7.99, $P=0.03]$ and $\mathrm{VO}_{2 \max }[\mathrm{F}(1,7)=18.99, P<$

Table 2. Physical and laboratory parameters of the subjects before and after training.

\begin{tabular}{|c|c|c|c|c|c|c|c|}
\hline \multirow{2}{*}{ Parameter } & \multirow{2}{*}{ Group } & \multicolumn{2}{|c|}{ Training } & \multicolumn{3}{|c|}{ Two-way ANOVA (F-value) } & \multirow{2}{*}{ Post hoc test (Tukey’s HSD) } \\
\hline & & Before & After & Group & Training I & Interaction & \\
\hline Weight, kg & $\begin{array}{l}\text { Normoxia } \\
\text { Hypoxia }\end{array}$ & $\begin{array}{l}70.9 \pm 13.3 \\
71.4 \pm 14.5\end{array}$ & $\begin{array}{l}70.6 \pm 12.8 \\
70.5 \pm 13.5\end{array}$ & 0.01 & 1.10 & 0.30 & NS \\
\hline Body fat, \% & $\begin{array}{l}\text { Normoxia } \\
\text { Hypoxia }\end{array}$ & $\begin{array}{l}19.9 \pm 8.1 \\
20.0 \pm 8.3\end{array}$ & $\begin{array}{l}20.2 \pm 7.7 \\
18.8 \pm 7.9\end{array}$ & 0.74 & 1.14 & 4.40 & NS \\
\hline Waist circumference, cm & $\begin{array}{l}\text { Normoxia } \\
\text { Hypoxia }\end{array}$ & $\begin{array}{l}82.4 \pm 13.6 \\
83.0 \pm 14.7\end{array}$ & $\begin{array}{l}81.6 \pm 12.4 \\
80.8 \pm 13.4\end{array}$ & 0.01 & 2.86 & 1.39 & NS \\
\hline BMI, kg/m² & $\begin{array}{l}\text { Normoxia } \\
\text { Hypoxia }\end{array}$ & $\begin{array}{l}23.2 \pm 4.3 \\
23.4 \pm 4.6\end{array}$ & $\begin{array}{l}23.1 \pm 4.2 \\
23.1 \pm 4.4\end{array}$ & 0.04 & 1.44 & 0.30 & NS \\
\hline $\mathrm{S}_{\min }, \mathrm{mm}$ & $\begin{array}{l}\text { Normoxia } \\
\text { Hypoxia }\end{array}$ & $\begin{array}{l}0.8 \pm 0.7 \\
0.7 \pm 0.5\end{array}$ & $\begin{array}{l}0.7 \pm 0.7 \\
0.6 \pm 0.5\end{array}$ & 1.73 & 2.01 & 0.27 & NS \\
\hline $\mathrm{P}_{\max }, \mathrm{mm}$ & $\begin{array}{l}\text { Normoxia } \\
\text { Hypoxia }\end{array}$ & $\begin{array}{l}1.2 \pm 0.6 \\
1.2 \pm 0.6\end{array}$ & $\begin{array}{l}1.1 \pm 0.5 \\
1.1 \pm 0.6\end{array}$ & 0.003 & 3.37 & 0.88 & NS \\
\hline $\mathrm{S}_{\max }, \mathrm{mm}$ & $\begin{array}{l}\text { Normoxia } \\
\text { Hypoxia }\end{array}$ & $\begin{array}{l}1.7 \pm 1.1 \\
1.7 \pm 1.1\end{array}$ & $\begin{array}{l}1.6 \pm 1.1 \\
1.7 \pm 1.0\end{array}$ & 0.23 & $\begin{array}{c}7.99 \\
(P=0.03)\end{array}$ & 0.11 & NS \\
\hline ABI & $\begin{array}{l}\text { Normoxia } \\
\text { Hypoxia }\end{array}$ & $\begin{array}{l}1.02 \pm 0.08 \\
1.02 \pm 0.06\end{array}$ & $\begin{array}{l}1.08 \pm 0.06 \\
1.01 \pm 0.02\end{array}$ & 4.79 & $\begin{array}{c}1.59 \\
(P=0.03)\end{array}$ & 7.88 & $\begin{array}{l}\text { After training: Hypoxia }<\text { Normoxia } \\
\qquad(P=0.02)\end{array}$ \\
\hline $\mathrm{PWV}, \mathrm{cm} / \mathrm{s}$ & $\begin{array}{l}\text { Normoxia } \\
\text { Hypoxia }\end{array}$ & $\begin{array}{l}1149.9 \pm 153.1 \\
1100.1 \pm 174.8\end{array}$ & $\begin{array}{l}1188.4 \pm 148.0 \\
1047.1 \pm 173.1\end{array}$ & 8.43 & $\begin{array}{c}0.08 \\
(P=0.02)\end{array}$ & 3.34 & $\begin{array}{l}\text { After training: Hypoxia }<\text { Normoxia } \\
\qquad(P=0.02)\end{array}$ \\
\hline $\mathrm{VO}_{2 \max }, \mathrm{mL} / \mathrm{kg} / \mathrm{min}$ & $\begin{array}{l}\text { Normoxia } \\
\text { Hypoxia }\end{array}$ & $\begin{array}{l}53.3 \pm 8.4 \\
50.0 \pm 8.9\end{array}$ & $\begin{array}{c}54.9 \pm 10.3 \\
57.6 \pm 9.2\end{array}$ & 0.09 & $\begin{array}{l}18.99 \\
(P<0.001)\end{array}$ & ) 3.54 & $\begin{array}{l}\text { Hypoxia: Before }<\text { After training } \\
\qquad(P=0.04)\end{array}$ \\
\hline Glucose, mg/dL & $\begin{array}{l}\text { Normoxia } \\
\text { Hypoxia }\end{array}$ & $\begin{array}{l}92.4 \pm 11.4 \\
95.9 \pm 13.7\end{array}$ & $\begin{array}{l}92.8 \pm 10.8 \\
97.3 \pm 14.0\end{array}$ & 0.83 & 0.06 & 0.04 & NS \\
\hline Insulin, $u \mathrm{U} / \mathrm{mL}$ & $\begin{array}{l}\text { Normoxia } \\
\text { Hypoxia }\end{array}$ & $\begin{array}{c}4.5 \pm 1.5 \\
13.7 \pm 15.0\end{array}$ & $\begin{array}{l}3.7 \pm 1.3 \\
7.0 \pm 5.1\end{array}$ & 2.42 & 0.94 & 0.76 & NS \\
\hline HOMA-R & $\begin{array}{l}\text { Normoxia } \\
\text { Hypoxia }\end{array}$ & $\begin{array}{l}1.2 \pm 0.6 \\
3.7 \pm 4.6\end{array}$ & $\begin{array}{l}0.8 \pm 0.4 \\
1.8 \pm 1.5\end{array}$ & 3.82 & 1.34 & 0.72 & NS \\
\hline $\mathrm{TG}, \mathrm{mg} / \mathrm{dL}$ & $\begin{array}{l}\text { Normoxia } \\
\text { Hypoxia }\end{array}$ & $\begin{array}{c}112.9 \pm 54.3 \\
147.3 \pm 156.2\end{array}$ & $\begin{array}{l}91.1 \pm 57.6 \\
96.9 \pm 70.6\end{array}$ & 0.68 & 3.82 & 0.33 & NS \\
\hline TCHO, mg/dL & $\begin{array}{l}\text { Normoxia } \\
\text { Hypoxia }\end{array}$ & $\begin{array}{l}182.9 \pm 30.9 \\
176.4 \pm 26.3\end{array}$ & $\begin{array}{l}176.0 \pm 28.6 \\
176.4 \pm 29.7\end{array}$ & 0.19 & 0.87 & 1.03 & NS \\
\hline $\mathrm{HDL}, \mathrm{mg} / \mathrm{dL}$ & $\begin{array}{l}\text { Normoxia } \\
\text { Hypoxia }\end{array}$ & $\begin{array}{l}50.9 \pm 13.0 \\
50.1 \pm 13.3\end{array}$ & $\begin{array}{c}55.5 \pm 11.3 \\
53.6 \pm 9.4\end{array}$ & 1.52 & 5.13 & 0.11 & NS \\
\hline LDL, mg/dL & $\begin{array}{l}\text { Normoxia } \\
\text { Hypoxia }\end{array}$ & $\begin{array}{l}107.6 \pm 30.7 \\
102.9 \pm 23.4\end{array}$ & $\begin{array}{l}102.1 \pm 30.1 \\
105.6 \pm 30.3\end{array}$ & 0.01 & 0.27 & 1.28 & NS \\
\hline
\end{tabular}

BMI: Body mass index, $\mathrm{S}_{\min }$ : minimum thickness of subcutaneous fat; $\mathrm{P}_{\max }$ : Maximum thickness of preperitoneal fat; $\mathrm{S}_{\max }$ : Maximum thickness of subcutaneous fat; ABI: Ankle brachial index; PWV: Brachial ankle pulse wave velocity; $\mathrm{VO}_{2 \max }$ : Maximum oxygen uptake; HOMA: Homeostasis model assessment; TG: Triglycerides; TCHO: Total cholesterol; HDL: High-density lipoprotein cholesterol; LDL: Low-density lipoprotein cholesterol; TG: Triglycerides; NS: Not significant. 
0.001]. For PWV, significant main effect for the groups were observed $[\mathrm{F}(1,7)=8.43, P=0.02]$.

Subsequently, the PWV after training was signifycantly lower in the hypoxic group than in the normoxic group ( $P=0.02$, Figure 1). The $\mathrm{VO}_{2 \max }$ in the hypoxic group was significantly higher after training than before training $(P=0.04$, Figure 2$)$.

\section{DISCUSSION}

The present study concerns the influence of hypoxic physical exercise on metabolic risk markers, $\mathrm{VO}_{2 \max }$, and arterial stiffness in healthy subjects and, to our knowledge, is the first study with a same-subject repeatedmeasures design in controlled laboratory conditions. Although there were no effects on MS-related blood-test markers such as glucose and lipid parameters, we found a significant decrease in PWV, and a significant increase in $\mathrm{VO}_{2 \max }$. Our results suggest regular hypoxic exercise is not only associated with cardiorespiratory improvement but also prevention of arteriosclerosis.

Among patients with DM, increased physical activity or cardiorespiratory endurance capability is associated with substantially reduced risk of cardiovascular events [23-25]. A recent study demonstrated that higher levels of cardiorespiratory fitness protect against MS in older individuals [26]. Kumagai et al. [27] reported a high degree of cardiorespiratory fitness positively contributed to
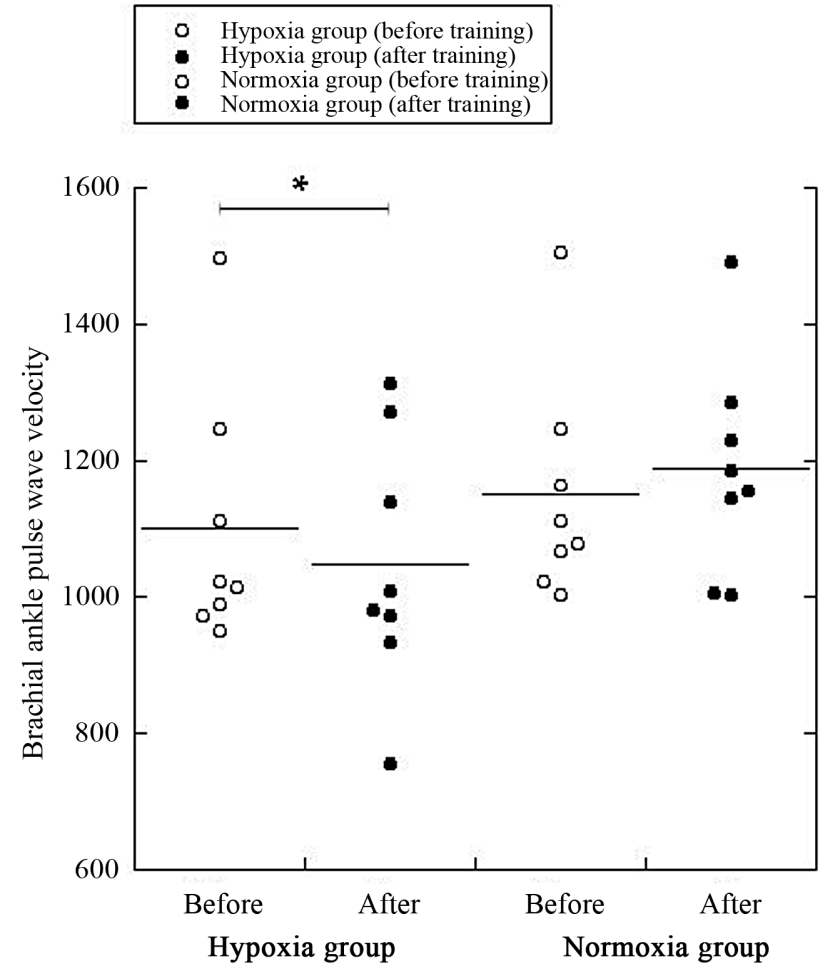

Figure 1. Changes in PWV before/after training in both normoxic and hypoxic groups. ${ }^{*} P<0.05$.

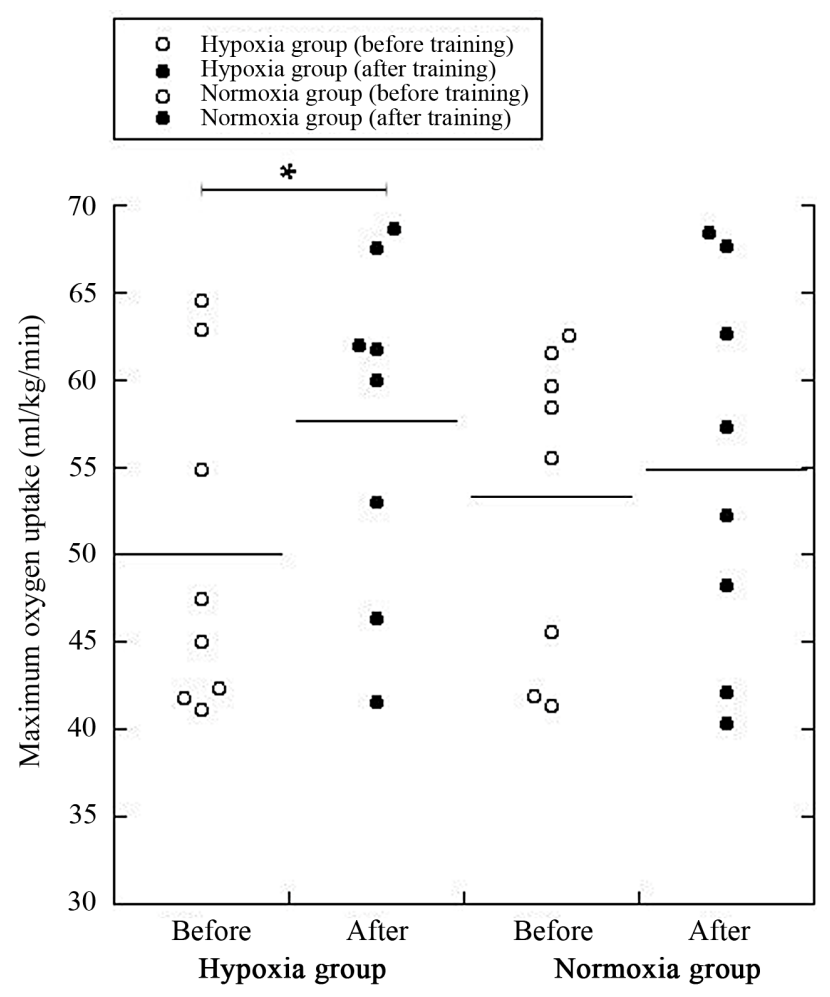

Figure 2. Changes in $\mathrm{VO}_{2 \max }$ before/after training in both Normoxic and Hypoxic groups. ${ }^{*} P<0.05$.

the low prevalence of MS in patients with impaired glucose tolerance and type $2 \mathrm{DM}$. $\mathrm{VO}_{2 \max }$ is commonly used in exercise testing to assess an individual's endurance capacity. Lakka et al. [28] investigated associations of recreational physical activity and cardiorespiratory fitness with $\mathrm{MS}$ the associations of $\mathrm{VO}_{2 \max }$ with the components of MS were stronger than those of physical activity. They emphasized that metabolic disorders may be suppressed by regular physical activity and maintenance of high $\mathrm{VO}_{2 \max }$ values. Our results indicate that $\mathrm{VO}_{2 \max }$ after 4 weeks of regular training increased significantly under the hypoxic condition compared with the normoxic condition; therefore, hypoxic training effected improvement of cardiorespiratory function. However, several investigators found unremarkable effects of hypoxic training on $\mathrm{VO}_{2 \max }$ in nonathletes. Wiesner et al. [15] evaluated the influence of normobaric hypoxia training on physical fitness in obese subjects; hypoxic exposure term was $60 \mathrm{~min}$. Meanwhile, in 10-hour simulated altitude conditions of $3000 \mathrm{~m}$ overnight, a significant increase in $\mathrm{VO}_{2 \max }$ was observed in the altitude group compared with the control [29]. Thus, we hypothesized that improvement of cardiorespiratory function was affected not only by exercise intensity but also by hypoxic exposure term.

The development of atherosclerosis increases the incidence of cardiovascular events such as heart attack or 
stroke. Hirai et al. [30] have shown strong associations between aortic stiffness and the degree of coronary artery disease, and similar associations have been reported between PWV and independently assessed cardiovascular risk scores [31]. PWV is generally assessed by measureing the time that the pulse wave takes to travel a given distance along the blood vessel; thus, it is an objective measurement of atherosclerosis. Nishiwaki et al. [17] demonstrated a significant increase in the percentage of flow-mediated vasodilation and a significant reduction in PWV after training in the hypoxic group in postmenopausal women. Their results indicate that hypoxic training may induce vascular functional adaptation. Our results also showed that PWV was significantly decreased in the post-hypoxic-training group compared with that in the normoxic-training group; these findings are in agreement with those previously reported. Meanwhile, reduced percentage of body fat, and values of laboratory parameters considered metabolic risk markers, were not observed after training. Several authors have investigated whether hypoxic training can induce MS-related marker reduction [13-15]. Netzer et al. [14] found no significant effect on lipids and HbA1c after normobaric hypoxic training $\left(15 \mathrm{Vol} \% \mathrm{O}_{2}\right)$ using a low intensity physical exercise $\left(60 \% \mathrm{VO}_{2 \max }\right)$, which resembled our study. Wiesner et al. [15] also investigated the hypoxic training effect on MS risk markers in obese subjects; their results showed no significant influence on blood pressure or LDL cholesterol. Our findings are also in agreement with previous studies that examined the effect of hypoxic training on MS risk markers. However, a few studies have reported decreased TG or insulin after short-term regular hypoxic training $[13,15]$. Further study with larger numbers of participants is needed for confirmation.

Our study has several limitations. First, the subjects were healthy young men, and our study did not include patients with metabolic disorders. Hence, we did not evaluate the pathological process and potential reduction of MS risk markers during regular hypoxic training. Second, the number of subjects was small, and our study design included before/after measurements with a control not a crossover study design. Third, the training duration was only 4 weeks; such short-term study does not provide information about long-term cardiorespiratory effects. To validate our findings, further studies are warranted with a larger number of participants and long-term monitoring using a crossover design. Further investigation is needed to confirm whether hypoxic training is related to MS risk marker reduction.

\section{CONCLUSION}

We found significant decreases in preperitoneal fat and $\mathrm{PWV}$, and a significant increase in $\mathrm{VO}_{2 \max }$, in the hypoxic group compared with the normoxic group. Our results suggest that regular hypoxic training may more effectively reduce arterial stiffness and improve cardiorespiratory parameters compared with training performed at the same relative exercise intensity under normoxic conditions.

\section{REFERENCES}

[1] Magliano, D.J., Shaw, J.E. and Zimmet, P.Z. (2006) How to best define the metabolic syndrome. Annals of Medicine, 38, 34-41. doi:10.1080/07853890500300311

[2] Alberti, K.G., Eckel, R.H., Grundy, S.M., Zimmet, P.Z., Cleeman, J.I., Donato, K.A., Fruchart, J.C., James, W.P., Loria, C.M. and Smith Jr., S.C. (2009) Harmonizing the metabolic syndrome: A joint interim statement of the International Diabetes Federation Task Force on Epidemiology and Prevention; National Heart, Lung, and Blood Institute; American Heart Association; World Heart Federation; International Atherosclerosis Society; and International Association for the Study of Obesity. Circulation, 120, 1640-1645.

doi:10.1161/CIRCULATIONAHA.109.192644

[3] Eberly, L.E., Prineas, R., Cohen, J.D., Vazquez, G., Zhi, X., Neaton, J.D. and Kuller, L.H. (2006) Metabolic syndrome: risk factor distribution and 18-year mortality in the multiple risk factor intervention trial. Diabetes Care, 29, 123-130. doi:10.2337/diacare.29.01.06.dc05-1320

[4] Braz, N.F., Carneiro, M.V., Oliveira-Ferreira, F., Arrieiro, A.N., Amorim, F.T., Lima, M.M., Avelar, N.C., Lacerda, A.C. and Peixoto, M.F. (2012) Influence of aerobic training on cardiovascular and metabolic parameters in ederly hypertensive women. International Journal of Preventive Medicine, 3, 652-659.

[5] Ha, C.H. and So, W.Y. (2012) Effects of combined exercise training on body composition and metabolic syndrome factors. Iranian Journal of Public Health, 41, 2026.

[6] Becker-Grunig, T., Klose, H., Ehlken, N., Lichtblau, M., Nagel, C., Fischer, C., Gorenflo, M., Tiede, H., Schranz, D., Hager, A., Kaemmerer, H., Miera, O., Ulrich, S., Speich, R., Uiker, S. and Grunig, E. (2012) Efficacy of exercise training in pulmonary arterial hypertension associated with congenital heart disease. International Journal of Cardiology. doi:10.1016/j.ijcard.2012.09.036

[7] Voulgari, C., Pagoni, S., Vinik, A. and Poirier, P. (2012) Exercise improves cardiac autonomic function in obesity and diabetes. Metabolism. doi:10.1016/j.metabol.2012.09.005

[8] Yoshida, H., Ishikawa, T., Suto, M., Kurosawa, H., Hirowatari, Y., Ito, K., Yanai, H., Tada, N. and Suzuki, M. (2010) Effects of supervised aerobic exercise training on serum adiponectin and parameters of lipid and glucose metabolism in subjects with moderate dyslipidemia. Journal of Atherosclerosis and Thrombosis, 17, 1160-1166. doi:10.5551/jat.4358

[9] Guo, W., Kawano, H., Piao, L., Itoh, N., Node, K. and Sato, T. (2011) Effects of aerobic exercise on lipid profiles and high molecular weight adiponectin in Japanese workers. Internal Medicine, 50, 389-395. 
doi:10.2169/internalmedicine.50.4380

[10] Hendriksen, I.J. and Meeuwsen, T. (2003) The effect of intermittent training in hypobaric hypoxia on sea-level exercise: A cross-over study in humans. European Journal of Applied Physiology, 88, 396-403. doi:10.1007/s00421-002-0708-Z

[11] Dufour, S.P., Ponsot, E., Zoll, J., Doutreleau, S., Lonsdorfer-Wolf, E., Geny, B., Lampert, E., Fluck, M., Hoppeler, H., Billat, V., Mettauer, B., Richard, R. and Lonsdorfer, J. (2006) Exercise training in normobaric hypoxia in endurance runners. I. Improvement in aerobic performance capacity. Journal of Applied Physiology, 100, 1238-1248. doi:10.1152/japplphysiol.00742.2005

[12] Roels, B., Bentley, D.J., Coste, O., Mercier, J. and Millet, G.P. (2007) Effects of intermittent hypoxic training on cycling performance in well-trained athletes. European Journal of Applied Physiology, 101, 359-368. doi:10.1007/s00421-007-0506-8

[13] Haufe, S., Wiesner, S., Engeli, S., Luft, F.C. and Jordan, J. (2008) Influences of normobaric hypoxia training on metabolic risk markers in human subjects. Medicine \& Science in Sports \& Exercise, 40, 1939-1944. doi:10.1249/MSS.0b013e31817f1988

[14] Netzer, N.C., Chytra, R. and Kupper, T. (2008) Low intense physical exercise in normobaric hypoxia leads to more weight loss in obese people than low intense physical exercise in normobaric sham hypoxia. Sleep Breath, 12, 129-134. doi:10.1007/s11325-007-0149-3

[15] Wiesner, S., Haufe, S., Engeli, S., Mutschler, H., Haas, U., Luft, F.C. and Jordan, J. (2010) Influences of normobaric hypoxia training on physical fitness and metabolic risk markers in overweight to obese subjects. Obesity (Silver Spring), 18, 116-120. doi:10.1038/oby.2009.193

[16] Vedam, H., Phillips, C.L., Wang, D., Barnes, D.J., Hedner, J.A., Unger, G. and Grunstein, R.R. (2009) Shortterm hypoxia reduces arterial stiffness in healthy men. European Journal of Applied Physiology, 105, 19-25. doi:10.1007/s00421-008-0868-6

[17] Nishiwaki, M., Kawakami, R., Saito, K., Tamaki, H., Takekura, H. and Ogita, F. (2011) Vascular adaptations to hypobaric hypoxic training in postmenopausal women. Journal of Physiological Sciences, 61, 83-91. doi:10.1007/s12576-010-0126-7

[18] Benso, A., Broglio, F., Aimaretti, G., Lucatello, B., Lanfranco, F., Ghigo, E. and Grottoli, S. (2007) Endocrine and metabolic responses to extreme altitude and physical exercise in climbers. European Journal of Endocrinology, 157, 733-740. doi:10.1530/EJE-07-0355

[19] Westerterp, K.R. (2001) Energy and water balance at high altitude. News in Physiological Science, 16, 134137.

[20] Pollock, M.L., Wilmore, J.H. and Fox, S.M. (1984) Exercise in health and disease: Evaluation and prescription for prevention and rehabilitation. W.B. Saunders, Philadelphia.

[21] Suzuki, R., Watanabe, S., Hirai, Y., Akiyama, K., Nishide, T., Matsushima, Y., Murayama, H., Ohshima, H., Shinomiya, M., Shirai, K., Saito, Y., Yoshida, S., Saisho, H. and Ohto, M. (1993) Abdominal wall fat index, esti- mated by ultrasonography, for assessment of the ratio of visceral fat to subcutaneous fat in the abdomen. American Journal of Medicine, 95, 309-314. doi:10.1016/0002-9343(93)90284-V

[22] Yamashina, A., Tomiyama, H., Takeda, K., Tsuda, H., Arai, T., Hirose, K., Koji, Y., Hori, S. and Yamamoto, Y. (2002) Validity, reproducibility, and clinical significance of noninvasive brachial-ankle pulse wave velocity measurement. Hypertension Research, 25, 359-364. doi:10.1291/hypres.25.359

[23] Church, T.S., Cheng, Y.J., Earnest, C.P., Barlow, C.E., Gibbons, L.W., Priest, E.L. and Blair, S.N. (2004) Exercise capacity and body composition as predictors of mortality among men with diabetes. Diabetes Care, 27, 83-88. doi:10.2337/diacare.27.1.83

[24] Wei, M., Gibbons, L.W., Kampert, J.B., Nichaman, M.Z. and Blair, S.N. (2000) Low cardiorespiratory fitness and physical inactivity as predictors of mortality in men with type 2 diabetes. Annals of Internal Medicine, 132, 605611.

[25] Hu, F.B., Stampfer, M.J., Solomon, C., Liu, S., Colditz, G.A., Speizer, F.E., Willett, W.C. and Manson, J.E. (2001) Physical activity and risk for cardiovascular events in diabetic women. Annals of Internal Medicine, 134, 96105.

[26] Hassinen, M., Lakka, T.A., Hakola, L., Savonen, K., Komulainen, P., Litmanen, H., Kiviniemi, V., Kouki, R., Heikkila, H. and Rauramaa, R. (2010) Cardiorespiratory fitness and metabolic syndrome in older men and women: the dose responses to Exercise Training (DR's EXTRA) study. Diabetes Care, 33, 1655-1657. doi:10.2337/dc10-0124

[27] Kumagai, S., Kai, Y., Nagano, M., Zou, B., Kishimoto, H. and Sasaki, H. (2005) Relative contributions of cardiorespiratory fitness and visceral fat to metabolic syndrome in patients with diabetes mellitus. Metabolic Syndrome and Related Disorders, 3, 213-220. doi:10.1089/met.2005.3.213

[28] Lakka, T.A., Laaksonen, D.E., Lakka, H.M., Männikkö, N., Niskanen, L.K., Rauramaa, R. and Salonen, J.T. (2003) Sedentary lifestyle, poor cardiorespiratory fitness, and the metabolic syndrome. Medicine \& Science in Sports \& Exercise, 35, 1279-1286. doi:10.1249/01.MSS.0000079076.74931.9A

[29] Neya, M., Enoki, T., Ohiwa, N., Kawahara, T. and Gore, C.J. (2012) Ten Hours Nightly Simulated Altitude at $3000 \mathrm{~m}$ Increases Hemoglobin Mass and $\mathrm{VO}_{2 \max }$. International Journal of Sports Physiology and Performance.

[30] Hirai, T., Sasayama, S., Kawasaki, T. and Yagi, S. (1989) Stiffness of systemic arteries in patients with myocardial infarction. A noninvasive method to predict severity of coronary atherosclerosis. Circulation, 80, 78-86. doi:10.1161/01.CIR.80.1.78

[31] Lehmann, E.D., Hopkins, K.D., Rawesh, A., Joseph, R.C., Kongola, K., Coppack, S.W. and Gosling, R.G. (1998) Relation between number of cardiovascular risk factors/events and noninvasive Doppler ultrasound assessments of aortic compliance. Hypertension, 32, 565-569. doi:10.1161/01.HYP.32.3.565 